\title{
ANTHROPOMETRIC AND PSYCHOPHYSIOLOGICAL CHARACTERISTICS OF TOP FEMALE VOLLEYBALLERS IN RELATION TO THE PLAYERS' POSITION ON THE COURT
}

\author{
KeIU PÕLluVEer, RAINI STAMM, MEELIS STAMM
}

Tallinn University, Estonia

\begin{abstract}
The aim of the current study was to find if the players who play in different positions in Estonian top female teams can be differentiated by their body build and psychophysiological characteristics. The study involved four female teams of the Estonian league: Viimsi Spa, Viljandi Metall, Tallinn University and the Junior National Team. In total, 41 female volleyballers were studied; they were divided as follows: first tempo attackers -13 , setters -8 , diagonal attackers -6 , second tempo attackers -9 , liberos -5 . Twelve anthropometric measurements were taken and eight indices were calculated from the measurement results. Psychophysiological tests were conducted, using the computer program Win Psycho, on all the 41 subjects three times during the season. Psychophysiological studies consisted in measuring simple and complex reaction times and anticipation time. Anthropometric and psychophysiological variables were statistically analysed according to the players' positions on the court. The mean values of variables of the four participating teams were also analysed.

Anthropometric data - both basic characteristics and indices - show great individual variability. However, there were statistically significant differences between the groups of players only in height, weight and horizontal arms spread. The results of psychophysiological tests did not differ statistically significantly between players in different positions. Still, the reaction times shortened towards the end of the season. The analysis of volleyballers' mean reaction times according to teams showed that the reaction times of three teams improved during the season. Tallinn University was the only team whose
\end{abstract}


reaction times worsened. Viljandi Metall was statistically significantly better compared to Viimsi Spa. Both of them were also the strongest clubs during the 2011/2012 season. Consequently, psychophysiological tests reflect the intensity and level of coaching in the teams.

Key words: female volleyballers in different positions, anthropometric measurements, psychophysiological tests.

\section{INTRODUCTION}

Literature shows that top female volleyballers differ by their anthropometric and psychophysiological characteristics. The differences are mainly physiological and constitutional, but some differences are also related to tactical tasks in accordance with the players' position on the court.

Thus, a difference is made between first tempo attackers, diagonal attackers, second tempo attackers, setters, and liberos. The player in each position is expected to have certain skills and qualities. First tempo attackers have to be tall, and quick at block. Diagonal attackers have to be strong, and dominant at attacks. Setters have to be quick and often make decisions quicker than players in other positions.

The aim of the current study was to find if the players who play in different positions in Estonian top female teams can be differentiated by their body build and psychophysiological characteristics. Another aim was to study if the players' psychophysiological characteristics change during the season and are related to the place achieved by their team in the Estonian championships of the 2011-2012 season.

\section{METHODS}

The study involved four female teams of the Estonian league: Viimsi Spa, Viljandi Metall, Tallinn University and the Junior National Team. At least ten players from each team took the tests and gave the measurements - in total, 41 female volleyballers (mean age $20.37 \pm 4.76$ years). Each team was represented by at least one player in each of the positions. According to positions, the subjects were divided as follows: first tempo attackers -13 , setters -8 , diagonal attackers -6 , second tempo attackers -9 , liberos -5 . 


\section{Methods of anthropometric measurements}

Twelve anthropometric measurements were taken: body height, body weight, upper chest circumference, waist circumference, hip circumference, upper thigh circumference, upper and lower leg circumference, arm circumference, arm circumference flexed and tensed, wrist circumference, and horizontal arms spread. Weight was measured on electronic scales and circumferences with a metal measuring tape. The measurements were taken with the precision of $\pm 0.5 \mathrm{~kg}$ and $\pm 0.5 \mathrm{~cm}$ by the same person at all times according to the method of Martin (Knussmann 1988) [5]. The measurements were taken once during the period October-November 2011 and, based on their results, the following anthropometric indices were calculated:

Body mass index

$$
\frac{\text { weight }}{\text { height }^{2}} \times 10000
$$

Relative upper chest circumference

$$
\frac{\text { upper chest circumference }}{\text { body height }} \times 100
$$

Relative waist circumference $\frac{\text { waist circumference }}{\text { bodyheight }} \times 100$

Relative wrist circumference

$$
\frac{\text { wrist circumference }}{\text { body height }} \times 100
$$

Relative hip circumference

$$
\frac{\text { hip circumference }}{\text { body height }} \times 100
$$

Relative arm circumference

$$
\frac{\text { arm circumference }}{\text { body height }} \times 100
$$

Relative upper thigh circumference

$$
\frac{\text { upperthigh circumference }}{\text { body height }} \times 100
$$

Relative waist-hip circumference

$$
\frac{\text { waist circumference }}{\text { hip circumference }} \times 100
$$

\section{Psychophysiological tests}

Psychophysiological tests were conducted using the computer program Win Psycho $2000[15,16]$. The tests were conducted on players of different 
positions in all teams $(n=41)$ in three stages: stage 1 - beginning of the season, October 2011; stage 2 - middle of the season, January 2012; stage 3 end of the season, April 2012.

The tests were of two kinds. Some measured simple reactions where the reaction time was measured by means of auditory stimulus to which the subject had to react immediately. Three series were performed, eight attempts in each series. The series differed from one another by the strength and pitch of sound. The program calculateed the mean reaction time for each subject separately for the right and the left hand.

The tests of the second kind measured complex reactions or determination of the speed of a moving object. The subjects first had to assess the motion speed of an object on the computer screen (fast or slow) and then take a decision. The program fixed the time of taking the decision. Each subject had to perform three series, eight attempts in each series. The program gives the mean results of each subject about the correctness of assessing the speed and the length of the time taken on decision-taking. The results of the test are considered better if the subject achieves more correct results in shorter time.

In addition, the anticipation time was calculated for each player. By anticipation the volleyballer's speed and precision of reacting to different stimuli is assessed. To do so, from the best result of the test of assessment of the speed of a moving object, the shortest time of simple reaction to an auditory stimulus was subtracted.

\section{Statistical analysis}

Statistical analysis of data was performed by Master of Mathematical Statistics Säde Koskel. First of all, primary analysis of anthropometric and psychophysiological variables was performed where the arithmetic mean, standard deviation, minimum and maximum values were found.

Thereafter, the players were divided according to their positions on the court as follows: first tempo attackers, diagonal attackers, second tempo attackers, liberos, setters. For each position, the mean values of all anthropometric measurements and psychophysiological tests results, their minimum and maximum values and standard deviations were found. Then, the significance of differences in the means was checked by the t-test.

The players' anthropometric differences, times of simple reaction and perception of speed of movement were assessed by groups of players in different positions and also by teams, and the differences of the means were checked by the t-test. 
As reaction speed tests and tests of perception of motion speed were performed at three stages, the players were longitudinally compared by teams to find if the reaction times the team shortened or lengthened. The tests results were also compared with the places achieved at the Estonian championships.

The height and weight of our volleyballers were compared with the mean height and weight of Estonian women of the same age.

Then, linear correlation analysis of anthropometric variables and psychophysiological tests results was performed, and thereafter correlations between anthropometric variables and tests results were found.

Volleyballers' body build data were divided into five body build classes small, medium, large, pycnomorphous and leptomorphous [12].

\section{RESULTS}

\section{Research results of anthropometric variables}

Table 1. Basic statistics of female volleyballers anthropometric variables $(n=41)$

\begin{tabular}{lcccc}
\hline Value & Min & Max & $\overline{\mathrm{x}}$ & $\mathrm{SD}$ \\
\hline Age & 13 & 41 & 20.366 & 4.76 \\
\hline Weight $(\mathrm{kg})$ & 58 & 82.8 & 70.912 & 5.521 \\
\hline Height $(\mathrm{cm})$ & 167 & 187 & 177.09 & 4.87 \\
\hline Upper chest circumference $(\mathrm{cm}$ & 68 & 95 & 88.61 & 4.97 \\
\hline Waist circumference $(\mathrm{cm})$ & 66 & 86 & 76.24 & 4.56 \\
\hline Hip circumference $(\mathrm{cm})$ & 90 & 113 & 101.81 & 4.55 \\
\hline Upper thigh circumference $(\mathrm{cm})$ & 53 & 66 & 59.42 & 2.91 \\
\hline Upper leg circumference $(\mathrm{cm})$ & 34 & 41 & 38 & 2.03 \\
\hline Lower leg circumference $(\mathrm{cm})$ & 21 & 28 & 24.51 & 1.50 \\
\hline Wrist circumference $(\mathrm{cm})$ & 15 & 18 & 16.56 & 0.74 \\
\hline Horizontal arms spread $(\mathrm{cm})$ & 163 & 194 & 179.93 & 7.05 \\
\hline Arm circumference $(\mathrm{cm})$ & 23 & 31 & 27.68 & 1.85 \\
\hline Arm circumference flexed and tensed $(\mathrm{cm})$ & 25 & 33 & 29.45 & 1.88 \\
\hline
\end{tabular}

The table shows great individual variability of anthropometric characteristics $24.8 \mathrm{~kg}$ in weight, $20 \mathrm{~cm}$ in height and 28 years in age. All the other bodily characteristics also vary accordingly. 
Table 2. Mean values of female volleyballers' variables according to positions $(n=41)$

\begin{tabular}{|c|c|c|c|c|c|}
\hline Value & $\begin{array}{c}\text { Diagonal } \\
\text { attackers } \\
\overline{\mathrm{x}} \\
\end{array}$ & $\begin{array}{l}\text { Liberos } \\
\overline{\mathrm{x}}\end{array}$ & $\begin{array}{c}\text { Setters } \\
\overline{\mathrm{x}}\end{array}$ & $\begin{array}{c}\text { First } \\
\text { tempo } \\
\text { attackers } \\
\overline{\mathrm{x}}\end{array}$ & $\begin{array}{c}\text { Second } \\
\text { tempo } \\
\text { attackers } \\
\overline{\mathrm{x}}\end{array}$ \\
\hline Weight (kg) & 73.68 & 69.46 & 67.05 & 74.35 & 68.33 \\
\hline Height $(\mathrm{cm})$ & 176.3 & 171.5 & 175.1 & 181.58 & 176.0 \\
\hline Upper chest circumference $(\mathrm{cm})$ & 91.5 & 88.8 & 88.0 & 88.9 & 86.7 \\
\hline Waist circumference $(\mathrm{cm})$ & 78.7 & 75.6 & 74.3 & 76.9 & 75.8 \\
\hline Hip circumference $(\mathrm{cm})$ & 103.8 & 100.6 & 99.4 & 104.3 & 99.7 \\
\hline Upper thigh circumference $(\mathrm{cm})$ & 61.5 & 59.6 & 58.1 & 60.0 & 58.2 \\
\hline Upper leg circumference $(\mathrm{cm})$ & 38.0 & 39.8 & 37.0 & 38.2 & 37.7 \\
\hline Lower leg circumference $(\mathrm{cm})$ & 24.5 & 24.8 & 24.3 & 24.9 & 24.0 \\
\hline Wrist circumference $(\mathrm{cm})$ & 16.7 & 16.8 & 16.4 & 16.8 & 16.2 \\
\hline Horizontal arms spread $(\mathrm{cm})$ & 179.2 & 172.7 & 177.7 & 184.1 & 180.3 \\
\hline Arm circumference $(\mathrm{cm})$ & 28.8 & 28.6 & 27.3 & 27.3 & 27.3 \\
\hline $\begin{array}{l}\text { Arm circumference flexed and } \\
\text { tensed }(\mathrm{cm})\end{array}$ & 30.5 & 30.0 & 29.1 & 29.1 & 29.2 \\
\hline
\end{tabular}

Here we can see that first tempo attackers and diagonal attackers were the players with largest anthropometric dimensions. Five variables in both groups of players were greater than in players in all other positions.

First tempo attackers had the biggest body height, body weight, hip circumference, lower leg circumference and horizontal arms spread.

Diagonal attackers had the biggest upper chest circumference, waist circumference, upper thigh circumference, arm circumference, and flexed and tensed arm circumference.

The smallest among the Estonian top female volleyballers were setters who had as many as four anthropometric characteristics that were the smallest among all the groups. These were body weight, waist circumference, hip circumference and upper leg circumference.

Second tempo attackers also had smaller dimensions than players in other positions. They had the smallest values of the following three characteristics upper chest circumference, lower leg circumference and wrist circumference.

Liberos also had two variables by which they were smaller than other players - body height and horizontal arms spread. Interestingly, their wrist circumference $-16.8 \mathrm{~cm}$ - was the largest, like that of first tempo attackers. Upper leg circumference $-39.8 \mathrm{~cm}$ - can be larger because liberos have to be halfsquatting during most of the playing time. 
Table 3. Basic statistics of female volleyballers' anthropometric indices and body composition characteristics $(n=41)$

\begin{tabular}{lcccc}
\hline Value & Min & Max & $\overline{\mathrm{x}}$ & $\mathrm{SD}$ \\
\hline Body mass index & 19.02 & 25.70 & 22.62 & 1.64 \\
\hline Relative upper chest circumference & 37.36 & 54.39 & 50.08 & 3.09 \\
\hline Relative waist circumference & 37.71 & 49.71 & 43.09 & 2.81 \\
\hline Relative wrist circumference & 8.57 & 10.78 & 9.36 & 0.41 \\
\hline Relative hip circumference & 51.78 & 63.13 & 57.51 & 2.59 \\
\hline Relative arm circumference & 13.74 & 19.30 & 16.65 & 1.3 \\
\hline Relative upper thigh circumference & 29.12 & 37.13 & 33.58 & 1.90 \\
\hline Relative waist-hip circumference & 66.99 & 82.18 & 74.90 & 3.23 \\
\hline
\end{tabular}

The table shows that the mean body mass index of top female volleyballers was 22.62 .

Table 4. Mean values of anthropometric indices and body composition characteristics of female volleyballers in different positions $(n=41)$

\begin{tabular}{lccccc}
\hline Value & $\begin{array}{c}\text { First } \\
\text { tempo } \\
\text { attackers } \\
\overline{\mathrm{x}}\end{array}$ & $\begin{array}{c}\text { Diagonal } \\
\text { attackers } \\
\overline{\mathrm{x}}\end{array}$ & $\begin{array}{c}\text { Second } \\
\text { tempo } \\
\text { attackers } \\
\overline{\mathrm{x}}\end{array}$ & $\begin{array}{c}\text { Liberos } \\
\overline{\mathrm{x}}\end{array}$ & $\begin{array}{c}\text { Setters } \\
\overline{\mathrm{x}}\end{array}$ \\
\hline Body mass index & 22.57 & 23.75 & 22.07 & 23.63 & 21.84 \\
\hline $\begin{array}{l}\text { Relative upper chest } \\
\text { circumference }\end{array}$ & 49.0 & 51.9 & 49.3 & 51.8 & 50.2 \\
\hline Relative waist circumference & 42.4 & 44.7 & 43.1 & 44.1 & 42.4 \\
\hline Relative wrist circumference & 9.2 & 9.5 & 9.2 & 9.8 & 9.4 \\
\hline Relative hip circumference & 57.5 & 58.9 & 56.6 & 58.7 & 56.8 \\
\hline $\begin{array}{l}\text { Relative arm circumference } \\
\text { Relative upper thigh }\end{array}$ & 16.0 & 17.3 & 16.6 & 17.5 & 16.6 \\
\hline $\begin{array}{l}\text { circumference } \\
\text { Relative waist-hip }\end{array}$ & 33.1 & 34.9 & 33.1 & 34.8 & 33.2 \\
circumference & 73.8 & 75.8 & 75.9 & 75.2 & 74.8 \\
\hline
\end{tabular}

Table 4 reveals that the players with the highest body mass index were diagonal attackers and liberos. They are followed by first tempo attackers and second tempo attackers. Setters had the lowest body mass index. Comparison of the indices of different groups of players shows that, despite the first tempo attackers' larger height and weight, even four indices of them were lower than in other groups of players. There were relative chest circumference, relative waist circumference, relative arm circumference, relative waist-hip circumference. 
Diagonal attackers' indices had the highest value in four cases - relative chest circumference, relative waist circumference, relative hip circumference, and relative upper thigh circumference.

Despite their small height and weight, liberos had two indices with highest values. These were relative wrist circumference and relative arm circumference.

Statistical comparison of the mean values of all the above-mentioned basic characteristics and indices with the paired $\mathrm{t}$-test according to the players' position on the court showed significant differences in weight, height and horizontal arms spread. Thus, the weight of first tempo attackers and setters differed significantly; height differed significantly between first tempo attackers and second tempo attackers, between first tempo attackers and setters, and between first tempo attackers and liberos. Horizontal arms spread differed significantly between first tempo attackers and liberos.

It is noteworthy that there were so great differences in horizontal arms spread - up to $31 \mathrm{~cm}$. The shortest horizontal arms spread was $163 \mathrm{~cm}$ and the longest $194 \mathrm{~cm}$. The difference of $31 \mathrm{~cm}$ is very big considering the range of the player's defence play; one player is able to cover an area $31 \mathrm{~cm}$ broader than another. This is particularly important at blocking.

\section{Results of psychophysiological research}

Table 5. Summary results of psychophysiological tests of female volleyballers $(n=41)$

\begin{tabular}{lccc}
\hline & $\begin{array}{c}\text { Stage 1 } \\
\text { time sec }\end{array}$ & $\begin{array}{c}\text { Stage 2 } \\
\text { time sec }\end{array}$ & $\begin{array}{c}\text { Stage 3 } \\
\text { time sec }\end{array}$ \\
\hline $\begin{array}{l}\text { Simple reaction } \\
\text { Best time }\end{array}$ & 0.131 & 0.232 & 0.193 \\
\hline Slowest time & 0.893 & 0.526 & 0.632 \\
\hline Mean time & 0.327 & 0.323 & 0.305 \\
\hline Complex reaction (test of perception) & 0.47 & 0.47 & 0.49 \\
\hline Slowest time & 2.66 & 1.81 & 1.69 \\
\hline Mean time & 0.885 & 0.812 & 0.734 \\
\hline
\end{tabular}


Table 6. Comparison of simple reaction times (in seconds) of players in different positions $(n=41)$

\begin{tabular}{lccc}
\hline Diagonal attackers & $\begin{array}{c}\text { Stage 1 } \\
\text { time sec }\end{array}$ & $\begin{array}{c}\text { Stage 2 } \\
\text { time sec }\end{array}$ & $\begin{array}{c}\text { Stage 3 } \\
\text { time sec }\end{array}$ \\
\hline Liberos & 0.301 & 0.31 & 0.332 \\
\hline Setters & 0.307 & 0.30 & 0.320 \\
\hline Second tempo attackers & 0.342 & 0.323 & 0.309 \\
\hline First tempo attackers & 0.344 & 0.292 & 0.292 \\
\hline
\end{tabular}

Table 7. Anticipation time (best perception time - best simple reaction time) of players in different positions $(n=41)$

\begin{tabular}{lccc}
\hline & $\begin{array}{c}\text { Stage 1 } \\
\text { time sec }\end{array}$ & $\begin{array}{c}\text { Stage 2 } \\
\text { time sec }\end{array}$ & $\begin{array}{c}\text { Stage 3 } \\
\text { time sec }\end{array}$ \\
\hline Diagonal attackers & 0.52 & 0.54 & 0.45 \\
\hline Liberos & 0.49 & 0.51 & 0.41 \\
\hline Second tempo attackers & 0.46 & 0.42 & 0.37 \\
\hline Setters & 0.46 & 0.49 & 0.43 \\
\hline First tempo attackers & 0.69 & 0.5 & 0.45 \\
\hline
\end{tabular}

As Table 5 shows, both simple and complex reaction times were different in three stages of testing, but the mean reaction times gradually improved and were the shortest at the end of the season.

Comparison of simple reaction times according to positions (Table 6) also shows shortening of times at the third time of testing. The same can be seen when anticipation times of players in different positions are compared at three stages of testing.

In conclusion, however, statistical analysis did not reveal any significant differences between players in different positions.

Next, the volleyballers' mean reaction times were analysed according to teams.

Here we can see that the mean reaction times of three teams improved during the season. Tallinn University was the only team whose reaction times worsened.

Statistically significantly, the team of Viljandi Metall was better than Viimsi Spa. Those two were also the two strongest clubs during the 2011/2012 season. 
Table 8. The best mean reaction times of four teams during the season

\begin{tabular}{lccc}
\hline Viimsi Spa & $\begin{array}{c}\text { Stage 1 } \\
\text { Time sec }\end{array}$ & $\begin{array}{c}\text { Stage 2 } \\
\text { Time sec }\end{array}$ & $\begin{array}{c}\text { Stage 2 } \\
\text { Time sec }\end{array}$ \\
\hline Viljandi Metall & 0.331 & 0.288 & 0.274 \\
\hline Junior national team & 0.321 & 0.311 & 0.298 \\
\hline Tallinn University & 0.335 & 0.332 & 0.319 \\
\hline
\end{tabular}

\section{Results of correlation analysis between anthropometric measurements and psychophysiological tests results}

In the whole sample, the anthropometric characteristics in significant correlation were height and weight $(\mathrm{r}=0.453)$. Height correlated significantly with horizontal arms spread $(r=0.779)$ and weight with all circumferences, most of all with hip circumference $(r=0.884)$.

Mutual correlations between anthropometric indices were also significant $(r=0.5-0.8)$ and between indices and basic characteristics.

Comparing the mean anthropometric variables of players in different positions by the t-test, we found that significant differences appeared in height, weight and horizontal arms spread. First tempo attackers were significantly heavier than setters. First tempo attackers were also significantly taller than second tempo attackers, setters and liberos. Horizontal arms spread was significantly larger in first tempo attackers than in liberos.

Thus, champion league players in different positions could be differentiated by their anthropometric variables. The reaction times in psychophysiological tests did not show any significant correlations with any basic anthropometric characteristics or indices.

\section{Classifying of players into a 5 SD classification of height and weight}

For simultaneous comparison of height and weight, we used a weight-height classification with the following SD classes: (1) small weight - small height, (2) medium weight - medium height, (3) big weight - big height, (4) pycnomorphs - big weight and small height, and (5) leptomorphs - small weight big height.

We found that almost $50 \%$ of players were in classes of concordant height and weight; in the small and big class - equally $17 \%$ of players. The largest number of players $(34.15 \%)$ belonged to the class of pycnomorphs and $17 \%$ to 
the class of leptomorphs. Thus, it can be concluded that a relatively great part of female volleyballers have bigger weight compared to their height.

\section{DISCUSSION}

Our research results on significant anthropometric differences between players in different positions are compatible with those published in literature. In our sample, the players with the greatest height and weight were first tempo attackers and diagonal attackers. The same is confirmed by literature $[1,6,13]$

Literature data on the height and weight of setters differ. At professional and international level, it is customary to use tall setters. The reason is not only the quality of setting but also greater abilities at blocking [9]. Others [1] find that speed and agility are more essential for setters than their athletic qualities. Thus, Gualdi-Russo and Zaccagni [3] and Malousaris et al. [8] have found that setters can be the lightest, shortest and quickest, and thus, their body mass index is also the smallest. Our setters had small weight and height.

In addition to height, larger horizontal arms spread, larger ankle breadth and larger wrist circumference are important. According to Grantov's study [2], bigger height provides better reach above the net; bigger ankle breadth gives greater stability at landing and blocking. Bigger wrist breadth contributes to hitting the ball during the attack. Larger trunk and strong muscles guarantee better performance of all the elements of the game. Loko [7] has emphasized the significance of this at selection of young players.

Our results also showed that diagonal attackers and first tempo attackers had the largest horizontal arms spread. Wrist circumference was the biggest in first tempo attackers and liberos, and lower leg circumference the biggest in first tempo attackers.

Comparison of the height of our female volleyballers $(177.09 \mathrm{~cm})$ with the data of other countries shows that the height of the women in the Estonian championship league was most similar to the players of the US first division $176.88 \mathrm{~cm}$ [10]. According to Zhang [14], the height, weight and body mass index of top female volleyballers have been increasing from the $26^{\text {th }}$ to the $29^{\text {th }}$ Olympic Games. Height had increased from 181 to $184 \mathrm{~cm}$ and weight from 71.4 to $73.4 \mathrm{~kg}$. The mean weight of Estonian volleyballers in our sample was $70.912 \mathrm{~kg}$.

The mean height of 20-year-old Estonian women was $167.89 \mathrm{~cm}$ [4], which is nearly ten centimetres shorter than that of top female volleyballers - 177.09. 
The mean weight of 20-year-old Estonian women $(60.65 \mathrm{~kg})$ was also nearly ten kilograms smaller than that of top female volleyballers $(70.912 \mathrm{~kg})$.

Consequently, the top female volleyballers are a selected sample. The significance of the anthropometric factor in the physical abilities, volleyball technical skills and psychophysiological computerized tests in 13-16-year-old female volleyballers has been studied by R. Stamm [11, 12]. According to her results, body build determined $42-89 \%$ of the results of physical abilities tests, up to $32 \%$ of volleyball technical tests and up to $43 \%$ of psychophysiological tests. Proficiency in the game depended both on the girls' body build and the results of all the tests used. Thus, attack, block, and feint were better performed by girls with bigger weight bigger circumferences of the arm, upper and lower leg who reacted more quickly to the changing situation in the game (anthropometric models $\mathrm{R}^{2}=0.71-0.83$, psychophysiological models $\mathrm{R}^{2}=$ $0.60-0.98)$. Proficiency of reception of serve depended on anthropometric variables and all the tests results within $39-50 \%$. The proficiency of serve was determined by anthropometric models within $1-32 \%$.

In the current study, all the subjects took the simple reaction test based on sound and the test on the ability of differentiating the speed of motion. The tests were conducted three times during the season using the computer program Win Psycho 2000. The players' best mean simple reaction time improved during the season from 0.327 to 0.323 to 0.305 seconds. The best mean complex reaction time also improved - from 0.885 to 0.823 to 0.734 seconds. The anticipation times also shortened during the season. During the whole season, the quickest players were second tempo attackers and the slowest diagonal attackers and first tempo attackers. Although differences were found between groups of players in psychophysiological tests results, these were not statistically significant.

Attention should be paid, however, to the mean reaction times of the teams. The t-test revealed that the team of Viljandi Metall was significantly quicker than Viimsi Spa and the Junior National Team. Comparison of the results of the third testing of the teams showed that mean reaction times of the Estonian champion Viljandi Metall and the second place holder Viimsi Spa were better than those of the two last clubs of the championship league (Tallinn University and the Junior National Team). Consequently, psychophysiological tests reflect the intensity and level of coaching in the teams. 


\section{ACKNOWLEDGEMENTS}

The study was supported by ESF and by Estonian Doctoral School of Educational Sciences project No. 1.2.0401.09-0070.

\section{REFERENCES}

1. Duncan M. I., Woodfield L., al-Nakeeb I. (2006). Anthropometric and physiological characteristics of junior elite volleyball players. Sports Medicine, 40, 649651.

2. Grantov Z., Katie R., Jankovic V. (2006). Morphological characteristics, technical and situation efficacy of young female volleyball players. University of Split. Collegium Anthropologicum, 30, 1, 87-96.

3. Gualdi-Russo E., Zaccagni L. (2001). Somatotype, role and performance in elite volleyball players. J Sports Med Phys Fitness, 41, 256-269.

4. Kaarma H., Saluste L., Lintsi M., Koskel J., Veldre G., Tiit E.-M., Koskel S., Arend A. (2008). Height and weight norms for adult Estonian men and women (aged 20-70 years) and ways of somatotyping using a height-weight classification. Papers on Anthropology XVII, 113-130.

5. Knussmann R. (1988). Anthropologie. Handbuch der vergleichenden Biologie des Menschen. Band I: Wesen und Methoden der Anthropologie. Stuttgart, New York: Gustav Fischer, 139-309.

6. Liik E. (2003). Volleyball manual. Estonian Volleyball Association. Tartu (in Estonian).

7. Loko J. (1999). Selection of young athletes. Tartu: Atlex. (in Estonian).

8. Malousaris G. G., Bergelesa N. K., Barzoukaa N. K., Bayiósa A. L., Nasris G. P., Koskolaub M. D. (2008). Somatotype, size and body composition of competitive female volleyball players. Journal of Science and Medicine in Sport, 11, 337-344.

9. Papageorgiu A., Spitzley W. (2003). Handbook for competitive volleyball. Oxford: Meyer \& Meyer Sport.

10. Schaal M. L. (2011). Physiologic performance test differences by competition level and player position in female volleyball athletes [Master's thesis]. Boise State University.

11. Stamm R., Veldre G., Stamm M., Thomson K., Kaarma H., Loko J., Koskel S. (2003). Dependence of young volleyballers' performance on their body build, physical abilities and psychophysiological properties. J Sports Med Phys Fitness, $43,1-9$.

12. Stamm R., Stamm M., Koskel S. (2006). Adolescent female volleyballers' (aged $13-15$ years) body build classification and proficiency in competitions. Anthropologische Anzeiger, 64 (4), 423-433.

13. Zelesnjak J. D., Ivoilov L. N. (1991). Volleyball. Fizkultura I Sport. Moscow (in Russian). 
14. Zhang Y. (2010). An investigation on the anthropometry profile and its relationship with physical performance of elite Chinese women volleyball players. [Master's thesis] Southern Cross University.

15. Thomson K. (1996). Software program for psychological research. Tallinn (in Estonian).

16. Thomson K. (2009). Study materials of sports psychology. PowerPoint slides (in Estonian).

\section{Address for correspondence:}

Meelis Stamm

Educational Science Institute

Tallinn University

Sireli 4, Tallinn, 10913, Estonia

E-mail: mella@tlu.ee 